\title{
Composição química e digestibilidade ruminal in situ da forragem de quatro espécies do gênero Brachiaria
}

[Chemical composition and in situ ruminal degradability of four Brachiaria species]

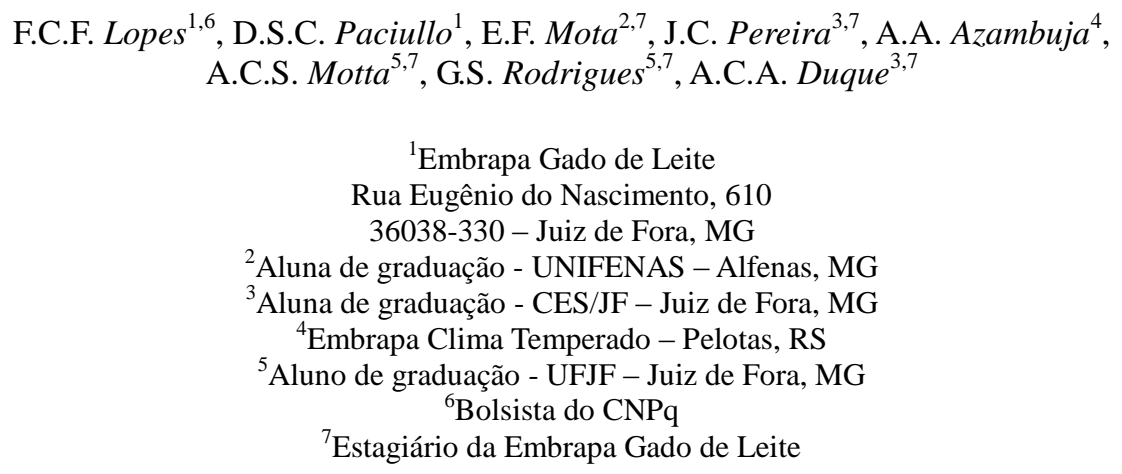

\section{RESUMO}

Avaliaram-se a composição química e a cinética da digestibilidade ruminal in situ da matéria seca (MS), proteína bruta (PB) e fibra em detergente neutro (FDN) da forragem de quatro espécies de Brachiaria, com 56 dias de crescimento, coletadas por corte manual. Foram utilizadas três vacas mestiças Holandês x Zebu, fistuladas no rúmen. Foram observados teores de 21,0;21,1;20,5 e 19,6\% de MS; 7,5; 6,4; 6,8 e $7,0 \%$ de PB; e 66,8; 70,1; 73,4 e 63,9\% de FDN, respectivamente, para B. brizantha, B. decumbens, $B$. humidicola e B. ruziziensis. O maior valor nutricional foi da B. ruziziensis, que apresentou as mais elevadas taxas de degradação e degradabilidades efetivas (DE) da MS e da PB, e o menor teor de FDN associado à maior taxa de degradação desse nutriente. A forragem de pior qualidade nutricional foi $B$. humidicola, com menores valores de DE da MS e PB e maiores concentrações das frações fibrosas e indigestíveis.

Palavras-chave: bovino, Brachiaria decumbens, Brachiaria brizantha, Brachiaria humidicola, Brachiaria ruziziensis

\begin{abstract}
The chemical composition and the ruminal in situ degradability of dry matter (DM), crude protein $(C P)$, and neutral detergent fiber (NDF) of four species of Brachiaria were evaluated. The forages were harvested at 56 days of growth. Three rumen-fistulated crossbred Holstein $\times$ Zebu cows were used. The chemical composition of $\mathrm{B}$. brizantha, B. decumbens, B. ruziziensis, and B. humidicola forages were, respectively: 21.0, 21.1, 20.5, and 19.6\% for DM; 7.5, 6.4, 6.8, and 7.0\% for CP; and 66.8, 70.1, 73.4, and $63.9 \%$ for $N D F$. B. ruziziensis presented the best nutritional value among the Brachiaria species, as indicated by the highest effective degradability (ED) and ruminal degradation rates of both DM and CP. B. ruziziensis also showed the highest NDF ruminal degradation rate and the lowest NDF concentration. In contrast, B. humidicola showed the worst nutritional composition, as indicated by the lowest DM and $C P E D$ values and the highest content of indigestible and fibrous fractions.
\end{abstract}

Keywords: cattle, Brachiaria decumbens, Brachiaria brizantha, Brachiaria humidicola, Brachiaria ruziziensis

Recebido em 13 de março de 2009

Aceito em 16 de julho de 2010

E-mail: fernando@cnpgl.embrapa.br 


\section{INTRODUÇÃO}

Segundo Alvim et al. (2002), dos 100 milhões de hectares de pastagens cultivadas no Brasil, aproximadamente 70 milhões são constituídos por espécies de gênero Brachiaria, sendo $B$. decumbens (Stapf.), B. humidicola (Rendle) Schweickt, $B$. brizantha (Stapf.) e B. ruziziensis (Germain e Everard) as mais utilizadas para formação de pastagens. Assim, a avaliação do valor nutricional e dos parâmetros de fermentação ruminal dessas espécies de Brachiaria faz-se importante, visando a sua eficiente utilização na alimentação de ruminantes.

A despeito de preocupações no tocante à sua padronização (Nocek, 1988; Nutrient..., 2001), a técnica in situ (Mehrez e Ørskov, 1977) tem sido amplamente utilizada e recomendada para estimar parâmetros de degradação ruminal. A forma modificada da equação proposta por Mehrez e Ørskov (1977) identifica, de modo explícito, dois dos principais elementos de qualificação de forrageiras, quais sejam: a taxa e o potencial de degradação (Sampaio et al., 1995). Para responder pelos efeitos inerentes à dinâmica da passagem da digesta no rúmen, Ørskov e McDonald (1979) sugeriram o uso de uma equação para obtenção de valores de degradabilidade efetiva dos nutrientes.

Foi objetivo deste estudo avaliar a composição química e a cinética da digestibilidade ruminal in situ da matéria seca, da proteína bruta e da fibra em detergente neutro da forragem de quatro espécies do gênero Brachiaria.

\section{MATERIAL E MÉTODOS}

O trabalho foi realizado no Campo Experimental de Coronel Pacheco, MG, de propriedade da Embrapa Gado de Leite, localizado na Zona da Mata de Minas Gerais, na altitude de $435 \mathrm{~m}$. As coordenadas geográficas do local são $21^{\circ} 33^{\prime}$ de latitude Sul e $43^{\circ} 16^{\prime}$ de longitude Oeste. O clima da região é do tipo CwA (mesotérmico), segundo a classificação de Köppen, com precipitação média anual de $1.500 \mathrm{~mm}$. Nos meses de outubro a março, tem-se um verão normalmente quente e chuvoso, e, de abril a setembro, um inverno frio e seco.

Foram utilizadas três vacas mestiças Holandês $\mathrm{x}$ Zebu (H x Z), fistuladas no rúmen e dotadas de cânulas de borracha natural, com $110 \mathrm{~mm}$ de diâmetro interno de abertura (Kehl Ind. Com. Ltda., São Carlos, SP, Brasil). As vacas estavam no terço final da segunda lactação $(251 \pm 21$ dias $)$ e produziam, em média, $5,1 \mathrm{~kg} /$ dia de leite e pesavam, em média $473 \pm 21 \mathrm{~kg}$. Exceto durante o período da ordenha, realizada às seis horas da manhã, as três vacas permaneceram em piquete formado, predominantemente, por capim-braquiária (Brachiaria spp.), com disponibilidade de matéria seca suficiente para permitir seletividade no consumo do pasto. A composição química da forragem selecionada no piquete de capimbraquiária foi obtida de amostra de extrusa coletada após 30min de pastejo de uma vaca $\mathrm{H}$ x $\mathrm{Z}$ de $476 \mathrm{~kg}$, em lactação, fistulada no esôfago.

Foram incubadas, no rúmen das três vacas, amostras de forragem de quatro espécies de Brachiaria: B. decumbens (Stapf.) cv. Basilisk, $B$. humidicola (Rendle) Schweickt, $B$. brizantha (Stapf.) cv. Marandu e B. ruziziensis (Germain e Everard). As amostras utilizadas na incubação ruminal foram coletadas em 20/12/06 por meio de corte manual, na altura aproximada de $5 \mathrm{~cm}$ do nível do solo, em canteiros de $30 \mathrm{~m}^{2}$. Por ocasião da colheita, as plantas encontravam-se com 56 dias de crescimento, pois previamente havia sido efetuado corte de uniformização das parcelas, seguido de adubação de cobertura, realizada a lanço, à razão de $300 \mathrm{~kg} / \mathrm{h}$ a da fórmula NPK 10-06-10.

As forragens coletadas em cada canteiro foram homogeneizadas para originar uma única amostra de cada espécie de Brachiaria. Posteriormente, as quatro amostras de forragens foram pré-secadas por $72 \mathrm{~h}$ em estufa de ventilação forçada, regulada para $55^{\circ} \mathrm{C}$. Frações de cada forrageira foram moídas em moinho de facas dotado de peneira com abertura de malhas de $1 \mathrm{~mm}$ e analisadas quanto à digestibilidade in vitro da matéria seca (DIVMS) e quanto aos teores de matéria seca (MS), proteína bruta (PB), fibra em detergente neutro (FDN), fibra em detergente ácido (FDA), lignina, celulose, extrato etéreo (EE), cinzas, nitrogênio insolúvel em detergente neutro (NIDN) e em detergente ácido (NIDA), segundo procedimentos descritos por Silva e Queiroz (2002). Foram também realizadas análises para determinação das frações nitrogenadas e de carboidratos das forragens (Fox et al., 2003).

Para estudo da degradação ruminal in situ da MS, PB e FDN, a quantidade restante de forragem présecada de cada espécie de Brachiaria foi moída em moinho de facas dotado de peneira com abertura de malhas de $5 \mathrm{~mm}$, acondicionada em sacos de náilon $(10 \times 20 \mathrm{~cm}$ de dimensão; porosidade de $50 \mu ; 10$ a $20 \mathrm{mg}$ de amostra por $\mathrm{cm}^{2}$ de área de saco) e incubada no rúmen das três vacas $\mathrm{H} \times \mathrm{Z}$, seguindo as recomendações gerais de Nocek (1988). Antes da 
incubação, todos os sacos foram mergulhados em água (temperatura ambiente, 30min). Os referentes ao tempo zero $(\mathrm{S})$ foram retirados e congelados, sendo os demais colocados no rúmen e retirados seis, 24 e 96 horas após a incubação, conforme recomendado por Sampaio et al. (1995), e, em seguida, também congelados. Todos os sacos foram descongelados, lavados simultaneamente para padronizar o processo, secados por $72 \mathrm{~h}$ em estufa de ventilação forçada regulada para $55^{\circ} \mathrm{C}$ e pesados, e os resíduos analisados quanto aos teores de MS, PB e FDN.

Os parâmetros de degradação ruminal in situ da MS, PB e FDN foram estimados pelo processo iterativo do algoritmo Marquardt, com auxílio do procedimento para modelos não lineares (PROC NLIN) do SAS/2002. Os dados de degradação parcial de cada espécie de Brachiaria foram ajustados segundo a equação descrita em Sampaio et al. (1995), utilizando-se, simultaneamente, as três repetições disponíveis (vacas) e obedecendo às premissas apresentadas por Sampaio (1997). A discussão dos resultados foi feita pela comparação das estimativas dos parâmetros de degradação ruminal in situ de cada forrageira. Os cálculos da degradabilidade efetiva (DE) foram realizados conforme relatado por Ørskov e McDonald (1979), utilizando-se taxas de passagem no rúmen de 2,5 e $8 \% /$ h (The Nutrient..., 1984).

\section{RESULTADOS E DISCUSSÃO}

Baseando-se nos resultados de composição química (Tab. 1), observa-se melhor qualidade nutricional da $B$. brizantha e da B. ruziziensis, tendo em vista as maiores DIVMS e concentrações de $\mathrm{PB}$, e os menores teores de FDN e lignina. Além disso, a B. ruziziensis apresentou as menores frações indigestíveis $\mathrm{C}$ de nitrogênio e de carboidratos, e as maiores concentrações de carboidratos não fibrosos e de compostos nitrogenados não proteicos (Tab. 2).

Tabela 1. Composição bromatológica (\% da matéria seca) de quatro espécies de forrageiras do gênero Brachiaria, incubadas no rúmen de vacas fistuladas

\begin{tabular}{llllllllllll}
\hline Forragem & $\begin{array}{l}\text { MS } \\
(\%)\end{array}$ & PB & FDN & FDA & EE & LIG & CEL & NIDA & NIDN & Cinza & $\begin{array}{c}\text { DIVMS } \\
(\%)\end{array}$ \\
\hline B. brizantha & 21,0 & 7,5 & 66,8 & 36,8 & 1,9 & 3,3 & 30,8 & 0,17 & 0,25 & 8,7 & 62,5 \\
B. decumbens & 21,1 & 6,4 & 70,1 & 36,2 & 1,7 & 3,4 & 30,3 & 0,11 & 0,16 & 8,0 & 60,9 \\
B. humidicola & 20,5 & 6,8 & 73,4 & 38,2 & 2,3 & 3,5 & 31,9 & 0,19 & 0,47 & 8,9 & 59,3 \\
B. ruziziensis & 19,6 & 7,0 & 63,9 & 34,9 & 2,0 & 3,1 & 29,0 & 0,11 & 0,20 & 9,2 & 63,9 \\
\hline
\end{tabular}

MS: matéria seca; PB: proteína bruta; FDN: fibra em detergente neutro; FDA: fibra em detergente ácido; EE: extrato etéreo; LIG: lignina; CEL: celulose; NIDA: nitrogênio insolúvel em detergente ácido; NIDN: nitrogênio insolúvel em detergente neutro; DIVMS: digestibilidade in vitro da MS.

Tabela 2. Fracionamento de carboidratos ( $\%$ da matéria seca) e de nitrogênio (\% da proteína bruta) de quatro espécies de forrageiras do gênero Brachiaria, incubadas no rúmen de vacas fistuladas

\begin{tabular}{lccccccccc} 
& \multicolumn{3}{c}{$\begin{array}{c}\text { Fração do carboidrato } \\
\text { Forragem }\end{array}$} & \multicolumn{3}{c}{ \% da matéria seca) } & \multicolumn{4}{c}{$\begin{array}{c}\text { Fração do nitrogênio } \\
\text { \% da proteína bruta) }\end{array}$} \\
\cline { 2 - 11 } & $\mathrm{CT}$ & $\mathrm{CNF}$ & $\mathrm{B} 2$ & $\mathrm{C}_{\mathrm{CHO}}$ & $\mathrm{A}$ & $\mathrm{B} 1$ & $\mathrm{~B} 2$ & $\mathrm{~B} 3$ & $\mathrm{C}_{\mathrm{N}}$ \\
\hline B. brizantha & 81,9 & 16,6 & 57,4 & 7,9 & 23,4 & 1,7 & 54,1 & 6,7 & 14,1 \\
B. decumbens & 83,9 & 14,8 & 60,9 & 8,2 & 45,3 & 0,0 & 39,1 & 4,9 & 10,7 \\
B. humidicola & 82,1 & 11,7 & 61,9 & 8,5 & 17,8 & 8,3 & 30,5 & 25,8 & 17,5 \\
B. ruziziensis & 81,8 & 19,1 & 55,1 & 7,5 & 42,1 & 2,7 & 37,4 & 8,0 & 9,8 \\
\hline
\end{tabular}

CT: carboidratos totais; CNF: carboidratos não fibrosos; B2: fibra em detergente neutro disponível; $\mathrm{C}_{\mathrm{CHO}}$ : fração indigestível; A: compostos nitrogenados não proteicos; B1, B2 e B3: proteína verdadeira com alta, intermediária ou baixa taxa de degradação, respectivamente; $\mathrm{C}_{\mathrm{N}}$ : fração não fermentável e indisponível para o animal.

A B. humidicola foi a forragem de pior qualidade, o que pode ser comprovado pelo menor valor da DIVMS e pelas maiores concentrações de FDN, FDA e lignina. Ressalte- se que concentração de $\mathrm{PB}$ menor que $7 \%$ pode limitar o consumo de forrageiras de clima tropical (Milford e Minson, 1966), que, no caso da $B$. humidicola, foi de $6,8 \%$ da MS (Tab. 1). 
A B. decumbens apresentou qualidade nutricional intermediária, tendo em vista sua DIVMS e as concentrações médias de FDN, FDA, lignina e carboidratos não fibrosos. A despeito do menor teor de $\mathrm{PB}$, foi observada a mais elevada concentração de compostos nitrogenados não proteicos na $B$. decumbens, além de baixa fração indigestível da PB (Tab.1 e 2).

A forragem selecionada no piquete de capimbraquiária, obtida da amostra de extrusa coletada da vaca fistulada no esôfago apresentou 12,2\% de MS, $10,2 \%$ de PB (\% da MS), 66,8\% de FDN (\% da MS) e $56,3 \%$ de digestibilidade in vitro da MS. Estes resultados são indicativos da boa qualidade nutricional da forragem selecionada na pastagem, durante o período de incubação das amostras no rúmen.

Os valores médios apresentados por Valadares Filho et al. (2002) para B. brizantha e $B$. decumbens com 46 a 60 dias de crescimento foram, respectivamente, de 21,5 e $27,3 \%$ para
MS; 10,6 e $9,1 \%$ para $\mathrm{PB} ; 83,8$ e $80,0 \%$ para FDN; 43,6 e 40,0\% para FDA; 4,0 e 3,0\% para EE; e de 5,6 e $6,0 \%$ para lignina. Para $B$. ruziziensis com 46 a 60 dias de crescimento, esses autores encontraram valores de $24,2 \%$ de MS e $8,5 \%$ de PB. Todos esses valores foram mais elevados que os observados no presente estudo. Para $B$. humidicola com 31 a 45 dias de crescimento, os valores relatados foram de $6,4 \%$ de PB; $72,5 \%$ de FDN; $31,4 \%$ de FDA; $2,7 \%$ de EE; $3,9 \%$ de lignina e $58,6 \%$ de digestibilidade da MS.

O modelo não linear utilizado por Sampaio et al. (1995) ajustou-se de modo satisfatório aos dados de degradação parcial da MS, PB e FDN. Os coeficientes de determinação $\left(\mathrm{R}^{2}\right)$ obtidos para as curvas de degradabilidade destes nutrientes foram sempre superiores a 93\% (Tab. 3 a 5), sendo indicativos da adequacidade do modelo para caracterização do fenômeno de degradação ruminal in situ dessas forragens.

Tabela 3. Parâmetros de degradação ruminal in situ da matéria seca de quatro espécies de forrageiras do gênero Brachiaria

\begin{tabular}{lccccccccc}
\hline Forragem & $\mathrm{A}$ & $\mathrm{B}$ & $\mathrm{c}$ & $\mathrm{R}^{2}$ & $\mathrm{~S}$ & $\mathrm{~B} 1$ & $\mathrm{DE} 2$ & DE5 \\
$(\%)$ & $(\%)$ & $(\% / \mathrm{h})$ & $(\%)$ & $\begin{array}{c}\text { DE8 } \\
(\%)\end{array}$ & $\begin{array}{c}(\%) \\
(\%)\end{array}$ \\
\hline B. brizantha & 79,4 & 60,1 & 2,77 & 98,9 & 20,2 & 59,2 & 54,6 & 41,4 & 35,5 \\
B. decumbens & 76,5 & 55,2 & 2,52 & 97,7 & 19,8 & 56,7 & 51,4 & 38,8 & 33,4 \\
B. humidicola & 74,7 & 56,6 & 2,97 & 95,8 & 16,5 & 58,1 & 51,3 & 38,2 & 32,3 \\
B. ruziziensis & 75,9 & 52,1 & 3,63 & 97,7 & 23,5 & 52,4 & 57,3 & 45,5 & 39,9 \\
\hline
\end{tabular}

A: fração potencialmente degradável; B: fração potencialmente degradável sob ação da microbiota, se não houvesse tempo de colonização; c: taxa constante de degradação da fração potencialmente degradável por ação da microbiota; $\mathrm{R}^{2}$ : coeficiente de determinação do ajuste do modelo utilizado por Sampaio et al. (1995) aos dados de degradação parcial; S: fração solúvel + partículas com tamanho reduzido que atravessam os poros do náilon; B1: fração potencialmente degradável sob ação da microbiota $(\mathrm{A}-\mathrm{S})$; DE2, DE5 e DE8: degradabilidades efetivas calculadas, considerando-se taxas de passagem no rúmen $(\mathrm{k} 1)$ de $2 ; 5$ e $8 \% / \mathrm{h}$, respectivamente $(\mathrm{DE}=\mathrm{S}+((\mathrm{B} 1 * \mathrm{c}) /(\mathrm{c}+\mathrm{k} 1)))$.

Tabela 4. Parâmetros de degradação ruminal in situ da proteína bruta de quatro espécies de forrageiras do gênero Brachiaria

\begin{tabular}{lccccccccc}
\hline Forragem & $\mathrm{A}$ & $\mathrm{B}$ & $\mathrm{c}$ & $\mathrm{R}^{2}$ & $\mathrm{~S}$ & $\mathrm{~B} 1$ & $\mathrm{DE} 2$ \\
$(\%)$ & $(\%)$ & $(\% / \mathrm{h})$ & $(\%)$ & $\begin{array}{c}\mathrm{DE} 5 \\
(\%)\end{array}$ & $\begin{array}{c}\text { DE8 } \\
(\%)\end{array}$ \\
\hline B. brizantha & 80,7 & 52,3 & 2,80 & 97,8 & 39,0 & 41,7 & 63,3 & 54,0 & 49,8 \\
B. decumbens & 72,9 & 31,1 & 3,88 & 93,6 & 52,0 & 20,9 & 65,8 & 61,2 & 58,9 \\
B. humidicola & 70,9 & 49,7 & 3,17 & 96,1 & 30,7 & 40,2 & 55,4 & 46,3 & 42,1 \\
B. ruziziensis & 77,6 & 29,7 & 5,97 & 96,2 & 53,4 & 24,2 & 71,6 & 66,6 & 63,8 \\
\hline
\end{tabular}

A: fração potencialmente degradável; B: fração potencialmente degradável sob ação da microbiota, se não houvesse tempo de colonização; c: taxa constante de degradação da fração potencialmente degradável por ação da microbiota; $\mathrm{R}^{2}$ : coeficiente de determinação do ajuste dos dados ao modelo utilizado por Sampaio et al. (1995); S: fração solúvel + partículas com tamanho reduzido que atravessam os poros do náilon; B1: fração potencialmente degradável sob ação da microbiota (A - S); DE2, DE5 e DE8: degradabilidades efetivas calculadas, considerando-se taxas de passagem no rúmen $(\mathrm{k} 1)$ de $2 ; 5$ e $8 \% / \mathrm{h}$, respectivamente $(\mathrm{DE}=\mathrm{S}+((\mathrm{B} 1 * \mathrm{c}) /(\mathrm{c}+\mathrm{k} 1)))$. 
Tabela 5. Parâmetros de degradação ruminal in situ da fibra em detergente neutro de quatro espécies de forrageiras do gênero Brachiaria

\begin{tabular}{lccccccccc} 
Forragem & $\mathrm{A}$ & $\mathrm{B}$ & $\mathrm{c}$ & $\mathrm{R}^{2}$ & $\mathrm{~S}$ & $\mathrm{~B} 1$ & $\mathrm{DE} 2$ & $\mathrm{DE} 5$ \\
$(\%)$ & $(\%)$ & $(\% / \mathrm{h})$ & $(\%)$ & $\begin{array}{c}\text { DE8 } \\
(\%)\end{array}$ & $\begin{array}{c}(\%) \\
(\%)\end{array}$ \\
\hline B. brizantha & 76,8 & 73,3 & 2,61 & 98,3 & 3,2 & 73,6 & 44,9 & 28,4 & 21,3 \\
B. decumbens & 77,9 & 69,5 & 2,03 & 97,1 & 5,2 & 72,7 & 41,8 & 26,2 & 19,9 \\
B. humidicola & 75,3 & 67,7 & 2,43 & 95,0 & 5,1 & 70,2 & 43,6 & 28,1 & 21,5 \\
B. ruziziensis & 71,2 & 66,1 & 3,19 & 95,4 & 0,0 & 71,2 & 43,8 & 27,7 & 20,3 \\
\hline
\end{tabular}

A: fração potencialmente degradável; B = fração potencialmente degradável sob ação da microbiota, se não houvesse tempo de colonização; c: taxa constante de degradação da fração potencialmente degradável por ação da microbiota; $\mathrm{R}^{2}$ : coeficiente de determinação do ajuste dos dados ao modelo utilizado por Sampaio et al. (1995); S: fração solúvel + partículas com tamanho reduzido que atravessam os poros do náilon; B1: fração potencialmente degradável sob ação da microbiota (A - S); DE2, DE5 e DE8: degradabilidades efetivas calculadas, considerando-se taxas de passagem no rúmen $(\mathrm{k} 1)$ de 2,5 e $8 \% / \mathrm{h}$, respectivamente $(\mathrm{DE}=\mathrm{S}+((\mathrm{B} 1 * \mathrm{c}) /(\mathrm{c}+\mathrm{k} 1)))$.

Rodrigues et al. (2004) trabalharam com três acessos de $B$. brizantha cortada aos 42 e 63 dias e observaram valores de degradabilidade ruminal da MS nas faixas de 66,1 a $94,4 \%$ para a degradabilidade potencial (DP), 1,5 a $4,6 \% / \mathrm{h}$ para a taxa de degradação (c), e 43,0 a 55,7\% e 31,0 a $42,8 \%$ para as DE calculadas, respectivamente, considerando-se taxas de passagem de 2 e $5 \% / \mathrm{h}$ no rúmen. Em outro trabalho realizado para comparar a degradabilidade ruminal da MS de $B$. brizantha cv. Marandu (5,8 a 9,7\% de PB e 67,7 a 69,7\% de FDN), obtida em sistema silvipastoril onde a gramínea estava sob sombreamento por arbóreas ou em pastagens manejadas em monocultivo, Moreira et al. (2009) relataram valores nas faixas de 78,7 a $84,9 \%$ para DP; 2,1 a $3,0 \% /$ h para c; e 49,8 a $52,0 \%$ e 34,9 a $37,3 \%$ para DE calculadas, respectivamente, considerando-se taxas de passagem de 2 e 5\%/h no rúmen. Os valores desses parâmetros de degradação ruminal da MS obtidos no presente trabalho para $B$. brizantha (Tab. 3) estão todos situados nas faixas relatadas por Rodrigues et al. (2004) e bem próximos dos apresentados por Moreira et al. (2009).

A $B$. brizantha apresentou a maior DP da MS (A $=79,4 \%)$ e da PB $(\mathrm{A}=80,7 \%)$. No entanto, $\mathrm{a}$ despeito da maior concentração de $\mathrm{PB}(7,5 \%$ da MS) em relação às das outras espécies de Brachiaria avaliadas, a taxa de degradação deste nutriente foi a mais baixa $(\mathrm{c}=2,80 \% / \mathrm{h})$, o que impôs redução no valor calculado de $\mathrm{DE}$ da $\mathrm{PB}$ da B. brizantha (Tab. 4). Isso pode ser parcialmente explicado pelas baixas concentrações das frações nitrogenadas A e B1, e pelos elevados teores das frações B3 - proteína de lenta taxa de degradação - e C indigestível (Tab. 2).
Os maiores valores de DE da MS e da PB foram obtidos para a $B$. ruziziensis, principalmente por ter apresentado as maiores taxas de degradação (c), bem como as mais elevadas frações solúveis (S) da MS e PB, respectivamente, $\mathrm{c}=3,63$ e $5,97 \% / \mathrm{h}$, e $\mathrm{S}=23,5$ e $53,5 \%$ (Tab. 3 e 4 ). Convém destacar que esta espécie apresentou o segundo maior teor de PB na MS (7,0\%). As menores frações indigestíveis do nitrogênio e de carboidratos na $B$. ruziziensis contribuíram para o incremento nos valores de DE da MS e da PB. Além disso, as mais elevadas concentrações de carboidratos não fibrosos e de compostos nitrogenados não proteicos (Tab. 2) foram determinantes das maiores taxas de degradação da MS e da PB, observadas para esta Brachiaria (Tab. 3 e 4 ).

A B. humidicola apresentou os menores valores para as frações solúveis (S) e para DP e DE da MS e da PB (Tab. 3 e 4). Contribuíram para isto as mais elevadas frações indigestíveis $\mathrm{C}$ (carboidratos e nitrogênio), os menores teores de carboidratos não fibrosos, além das elevadas concentrações de proteínas com média e lenta taxa de degradação (Tab. 2). Além disso, a concentração de PB foi de apenas $6,8 \%$ da MS (Tab. 1).

Quanto à composição química, a $B$. decumbens também apresentou valores intermediários de DP e DE da MS. No entanto, obteve a maior DE da $\mathrm{PB}$, que pode ser justificada pela elevada taxa de degradação desse nutriente $(3,9 \% / \mathrm{h}$; Tab. 4), provavelmente, obtida em consequência da expressiva concentração de compostos nitrogenados não proteicos $(\mathrm{A})$ e reduzida fração indigestível C da PB (Tab. 2). 
Os valores de DE da FDN foram semelhantes entre as quatro espécies de Brachiaria (Tab. 5). Entretanto, destacou-se a $B$. ruziziensis pela mais elevada taxa de degradação desse nutriente $(\mathrm{c}=$ $3,2 \% / \mathrm{h}$ ), bem como pelas menores concentrações de FDN, de lignina e das frações dos carboidratos B2 (FDN disponível) e C (indigestível) na MS da forragem (Tab. 1 e 2).

\section{CONCLUSÕES}

A melhor qualidade nutricional da forragem de Brachiaria ruziziensis pode ser atribuída às maiores taxas de degradação e degradabilidade efetiva da matéria seca e da proteína bruta, além do menor teor de fibra em detergente neutro associado à maior taxa de degradação desse nutriente. A $B$. humidicola foi a forragem de pior qualidade, com menores valores de digestibilidade in vitro e in situ da matéria seca, e maior concentração das frações fibrosas e indigestíveis.

\section{AGRADECIMENTOS}

À FAPEMIG (Fundação de Amparo à Pesquisa do Estado de Minas Gerais), pelo apoio financeiro ao trabalho.

\section{REFERÊNCIAS BIBLIOGRÁFICAS}

ALVIM, M.J.; BOTREL, M.A.; XAVIER, D.F. As principais espécies de Brachiaria utilizadas no País. Juiz de Fora: Embrapa Gado de Leite, 2002. 4p. (Comunicado técnico, 22.).

FOX, D.G.; TYLUTKI, T.P.; TEDESCHI, L.O. et al. The Net Carbohydrate and Protein System for evaluating herd nutrition and nutrient excretion (CNCPS version 5.0). Model documentation. Ithaca: Cornell University, 2003. (Animal science mimeo, 213).

MEHREZ, A.Z.; ØRSKOV, E.R. A study of the artificial fiber bag technique for determining the digestibility of feeds in the rumen. J. Agric. Sci., v.88, p.645-650, 1977.

MILFORD, R.; MINSON, D.J. Intake of tropical pasture species. In: CONGRESSO INTERNACIONAL DE PASTAGENS, 9., 1996, São Paulo. Anais... São Paulo: DPA-SAA-SP, 1996. p.815-822.
MOREIRA, G.R.; SALIBA, E.O.S.; MAURÍCIO, R.M. et al. Avaliação da Brachiaria brizantha cv. marandu em sistemas silvipastoris. Arq. Bras. Med. Vet. Zootec., v.61, p.706-713, 2009.

NOCEK, J.E. In situ and other methods to estimate ruminal protein and energy digestibility. A review. J. Dairy Sci., v.71, p.2051-2069, 1988.

NUTRIENT requirements of dairy cattle. 7.ed. Washington: National Research Council, 2001. 381p.

ØRSKOV, E.R.; McDONALD, I. The estimation of protein degradability in the rumen from incubation measurements weighted according to rate of passage. J. Agric. Sci., v.92, p.499-503, 1979.

RODRIGUES, A.L.P.; SAMPAIO, I.B.M.; CARNEIRO, J.C. et al. Degradabilidade in situ da matéria seca de forrageiras tropicais obtidas em diferentes épocas de corte. Arq. Bras. Med. Vet. Zootec., v.56, p.658-664, 2004.

SAMPAIO, I.B.M. Métodos estatísticos aplicados à determinação de digestibilidade in situ. In: SIMPÓSIO INTERNACIONAL DE DIGESTIBILIDADE EM RUMINANTES, 1997, Lavras. Anais... Lavras: UFLA-FAEPE, 1997. p.165-178.

SAMPAIO, I.B.M.; PIKE, D.J.; OWEN, E. Optimal design for studying dry matter degradation in the rúmen. Arq. Bras. Med. Vet. Zootec., v.47, p.373-383, 1995.

THE NUTRIENT requirements of ruminant livestock - ARC. Suppl.1. London: CAB, 1984. $45 \mathrm{p}$.

SILVA, J.S.; QUEIROZ, A.C. Análise de alimentos: métodos químicos e biológicos. 3.ed. Viçosa: UFV, 2002. 235p.

VALADARES FILHO, S.C.; ROCHA JR., V.R.; CAPPELLE, E.R. Tabelas brasileiras de composição de alimentos para bovinos. Viçosa: UFV, 2002. 279p. 